\title{
Reconfiguração de um Serviço de Urgência Central Polivalente Face à Pandemia COVID-19
}

\section{Reconfiguration of a Multi-purpose Central Emergence Service in the Face of the COVID-19 Pandemic}

\section{Anabela Oliveira}

Palavras-chave: COVID-19; Pandemia; Serviço de Urgência Hospitalar

Keywords: COVID-19; Emergency Service, Hospital; Pandemics.

\section{Introdução}

A 11 de março de 2020, a Organização Mundial de Saúde (OMS) declarou o surto epidémico COVID-19 como pandemia global.

No dia 24 de fevereiro de 2020, o Centro Hospitalar Universitário Lisboa Norte (CHULN) foi ativado pela Direção Geral da Saúde (DGS), hospital de referência de segunda linha para a contenção da infeção pelo SARS-CoV-2.

A norma publicada pela DGS a 26 de março de $2020^{2}$ fase de mitigação, implicou uma alteração completa nos circuitos dos doentes ao nível do Serviço de Urgência Central (SUC) do Centro Hospitalar Universitário Lisboa Norte (CHULN), tendo em conta a transmissão comunitária do vírus e a necessidade de diminuir a sua propagação, minimizando a mortalidade associada sobretudo nos grupos de risco.

\section{SUC do CHULN na época pré-COVID-19}

Trata-se de uma Urgência Polivalente, centro de Trauma, polo da Urgência Metropolitana de Lisboa, um dos Centros de Tratamento endovascular do acidente vascular cerebral (AVC) e do tratamento neurocirúrgico da ruptura de aneurisma cerebral em regime de rotação com outros hospitais da região metropolitana de Lisboa.

A afluência média diária situa-se nos 500-600 adultos/dia.

O SUC do CHULN tem uma Equipa Médica Dedicada constituída por 11 especialistas de Medicina Interna e três especialistas de Pneumologia entre outros médicos que cumprem horário das 08 às 20 horas todos os dias úteis.

Logo no início de março, houve necessidade de se criar um circuito de doentes respiratórios suspeitos de acordo

Diretora do Serviço de Urgência Central, Centro Hospitalar Universitário de Lisboa Norte, Hospital de Santa Maria, Lisboa, Portugal

https://revista.spmi.pt - DOI:10.24950/rspmi/COVID19/Anabela Oliveira/S/2020 com a então, definição de caso suspeito que permitisse a sua separação do doente não suspeito. ${ }^{3}$ Esta foi sem dúvida, uma fase difícil, de grande inquietação para os profissionais de saúde dado o escasso conhecimento epidemiológico da doença e a ainda elevada pressão assistencial do Serviço de Urgência do CHULN.

\section{SUC do CHULN -COVID-19-fase de miti- gação}

Nesta altura o SUC cresceu para fora do seu espaço físico com a criação de áreas dedicadas para a observação de casos suspeitos de infeção pelo SARS-CoV-2.

Foram definidas duas áreas distintas: doente não crítico e doente crítico COVID-19.

\section{A área do doente não crítico COVID-19}

Área da triagem - Tendas cedidas pela Cruz Vermelha Portuguesa (Fig. 1) com presença de médico e enfermeiro

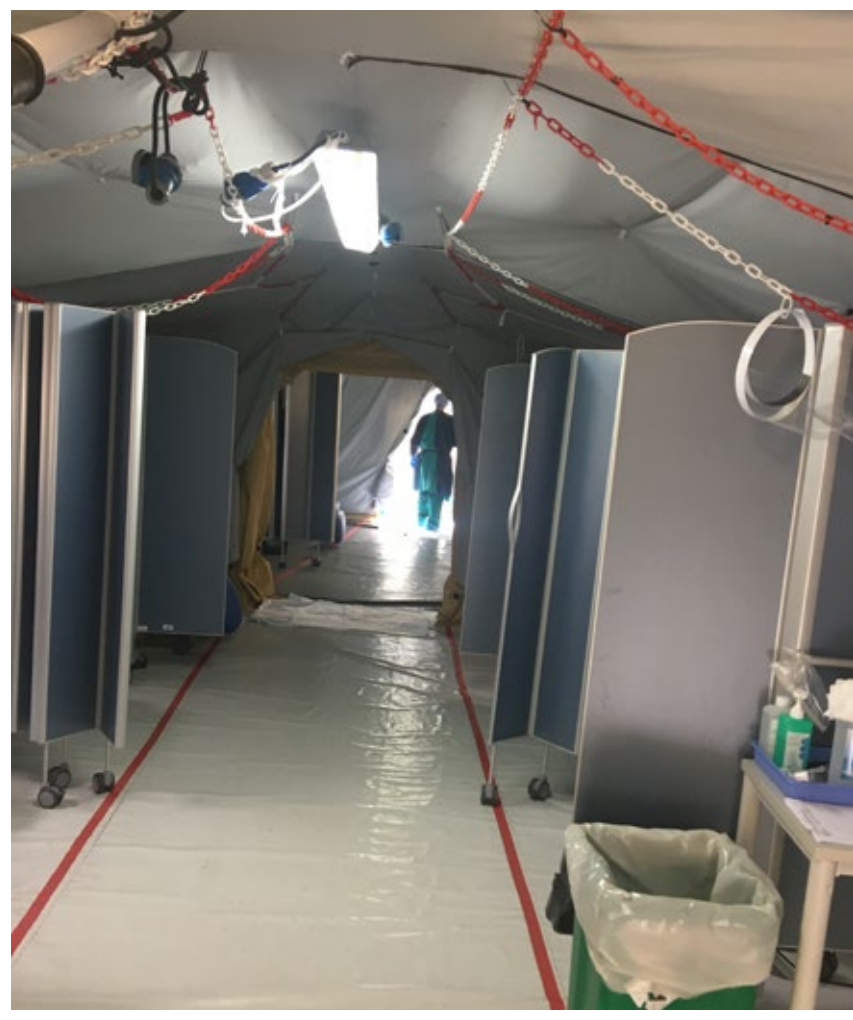

Figura 1: Tenda de Triagem COVID-19. 
onde é efetuada a separação de doentes suspeitos com sintomas ligeiros sem indicação para vigilância ou internamento e sem indicação para realização de meios complementares de diagnóstico e terapêutica (MCDT), de doentes com indicação para vigilância e /ou internamento.

Nesta área é realizado exsudado nasofaríngeo e orofaríngeo para teste molecular para SARS-CoV-2 e entregue ao doente o folheto de recomendações para isolamento social.

\section{Área dedicada ao doente COVID-19 para vigilância e /ou internamento}

Foi reconvertida uma área nevrálgica do CHULN, a Central de Consultas, o espaço físico com maior afluência de doentes e profissionais de saúde, em zona de observação de doentes com critérios clínicos para vigilância e/ou internamento.

Este espaço tem capacidade para 16 doentes com uma das boxes para observação de grávidas com suspeita de COVID-19.

A esta área ficou adstrita um aparelho de tomografia computorizada (TC) dedicado, tendo sido definidos "workflows" específicos para realização de TC torácica, exame importante na caracterização do envolvimento pulmonar por SARSCoV-2.4 Adjacente ao SUC, foi ainda colocado um contentor com 10 boxes individuais para observação de doentes suspeitos autónomos, ou com patologia oncológica ou imunossuprimidos.

\section{A área do doente crítico COVID-19}

Foi reconvertida toda a área de gabinetes Laranjas em área de doente crítico com suspeita de COVID-19. Nesta área, procedeu-se a intervenções estruturais básicas para assegurar a filtração e a renovação de ar de forma regular, com remoção de pressão positiva.

Nesta área, ficam alocados os doentes com indicação para intervenções terapêuticas geradoras de aerossóis como ventilação não invasiva (VNI).

A VNI tão útil em várias situações clínicas passou a ser contraindicada na maioria das situações em locais sem pressão negativa.

Para além da criação das condições atrás referidas, tiveram que ser implementados circuitos fechados para todos os doentes com indicação para esta técnica de ventilação. Colocaram-se neste processo dilemas éticos aos médicos que tiveram que manejar estas situações em ambiente de urgência.

\section{A área do doente não COVID-19}

O espaço físico original do SUC com exceção da área dos Laranjas manteve-se para o doente pouco suspeito de infeção por SARS-CoV-2.

Foram realocadas a outros espaços físicos a Urgência de Psiquiatria, ORL e Oftalmologia.
Estabeleceram-se circuitos de referenciação com o ACES Lisboa Norte para a patologia aguda não urgente.

\section{Recursos humanos}

Registou-se o "regresso" às equipas de Urgência, anteriormente com graves carências de recursos humanos, de internos de outras especialidades, ao mesmo tempo, que a contratação de novos profissionais tornou-se mais célere.

A dispersão dos recursos humanos pelos vários postos de trabalho tornou a gestão do Serviço de Urgência verdadeiramente desafiante.

Foi realizada formação dos novos profissionais que integraram as equipas de urgência no que concerne à utilização de equipamentos de proteção individual (EPI), aspeto fulcral na sua proteção.

Foi fundamental definir os grupos de profissionais mais dedicados ou "coorte" retirando para as áreas menos expostas os profissionais pertencentes a grupos de risco.

\section{Balanço}

Houve uma redução drástica da afluência de doentes ao SUC superior a 50\% até meados de abril, com doentes não COVID com descompensações muito graves das suas comorbilidades.

Registou-se um aumento da mortalidade de doentes no SUC quando comparado a período homólogo de 2019.

Alteração do "mindset" dos médicos na avaliação clínica de algumas situações facilmente abordáveis em ambiente de urgência.

Dificuldades a jusante no internamento de doentes, aumentando o tempo de permanência destes no SUC.

Sobreposição de infeção por SARS-CoV-2 com outras patologias, aumentando a intranquilidade dos profissionais de saúde.

Os hospitais passaram a ser vistos como reservatórios de infeções COVID-19 e deixaram de ser considerados como lugares seguros. ${ }^{5}$

\section{Futuro}

O futuro é imprevisível e está dependente de variáveis que não conseguimos controlar.

No final de maio na última fase do desconfinamento decretada pelo governo de Portugal, assistiu-se na zona metropolitana de Lisboa a vários surtos e casos esporádicos disseminados entre a população, o que nos "obriga" a manter ativos todos os circuitos de separação de doentes COVID-19 e COVID-19 "free".

É assim que o SUC do CHULN prepara-se novamente para mudar toda a área de observação de doentes COVID-19 para um novo contentor com capacidade para 28 doentes e com áreas de pressão negativa, libertando a entrada do hospital no retorno da atividade assistencial normal.

O cruzamento entre a epidemia de COVID-19 e a epidemia 
de gripe sazonal no inverno é uma incerteza e um motivo de grande inquietação.

A resiliência dos profissionais de saúde no SNS tem sido enorme e não é de hoje, mas arrasta-se há vários anos nomeadamente nos SU sobretudo, para os internistas que são o pilar fundamental do funcionamento dos serviços de urgência com problemas crónicos de "overcrowding" e de falta recorrente de recursos humanos. Na resposta que tem sido dada a esta Pandemia mais uma vez perfilaram-se como os principais "players" da chamada Linha da Frente.

\section{Agradecimento}

Um agradecimento a todos os meus colegas e colaboradores, alguns infetados neste percurso, ao Conselho de Administração do CHULN, ao Serviço de Instalação e Equipamentos, aos enfermeiros, assistentes operacionais e a todos os que ajudaram a reconfigurar um dos maiores Serviços de Urgência do país.

\section{Responsabilidades Éticas}

Conflitos de Interesse: Os autores declaram a inexistência de conflitos de interesse na realização do presente trabalho.

Fontes de Financiamento: Não existiram fontes externas de financiamento para a realização deste artigo.

Proveniência e Revisão por Pares: Comissionado; sem revisão externa por pares.

\section{Ethical Disclosures}

Conflicts of interest: The authors have no conflicts of interest to declare. Financing Support: This work has not received any contribution, grant or scholarship.

Confidentiality of Data: The authors declare that they have followed the protocols of their work center on the publication of data from patients.
Provenance and Peer Review: Commissioned; without externally peer reviewed.

(C) Autor (es) (ou seu (s) empregador (es)) 2020. Reutilização permitida de acordo com CC BY-NC. Nenhuma reutilização comercial.

(C) Author(s) (or their employer(s)) 2020. Re-use permitted under CC BYNC. No commercial re-use.

Correspondence / Correspondência:

Anabela Oliveira - anabela.oliveira@chln.min-saude.pt

Diretora do Serviço de Urgência Central, Centro Hospitalar Universitário de Lisboa Norte, Hospital de Santa Maria, Lisboa, Portugal

Avenida Professor Egas Moniz, 1649-035 Lisboa

Received / Recebido: 08/06/2020

Accepted / Aceite: 15/06/2020

Publicado / Published: 16 de Julho de 2020

\section{REFERÊNCIAS}

1. World Health Organization. WHO Director-General's opening remarques at the media briefing on COVID-19-11March 2020. [acedido Jun 2020] Disponivel em: https://www.who.int/dg/speeches/detail/ who-director-general-s-opening-remarks-at-the-media-briefing-on-covid-19-11-march-2020.

2. Direção Geral da Saúde. Norma n003/2020:COVID-19. Fase de Mitigação-Abordagem do doente com suspeita ou infeção por SARS-CoV-2. Lisboa: DGS; 2020

3. Direção Geral da Saúde. Orientação na002/2020 de 25/01/2020 atualizada a 909/03/2020. Doença pelo novo Coronavírus (COVID-19) -nova definição de caso. Lisboa: DGS; 2020.

4. Yan Li, Liming Xia. Coronavirus disease 2019 (COVID)-19: role of chest CT diagnosis and management. AJR Am J Roentgenol. 2020; 214:1280-6.

5. Wong LE, Hawkins JE, Langness S, Murrell KL, Iris P, Sammann A. Where are all the patients? Addressing COVID-19 fear to encourage sick patients to seek emergency care. [acedido Jun 2020] Disponível em: https://catalyst.nejm.org/doi/full/10.1056/CAT.20.0193. 